\title{
Reflexão sobre a ação na formação e prática docente: autoconhecimento e identidade profissional
}

\author{
Helena de Ornellas Sivieri-Pereira \\ Universidade Federal do Triângulo Mineiro - UFTM, Brasil \\ Dennis Gabiatti Lopes \\ Universidade Federal do Triângulo Mineiro - UFTM, Brasil \\ Renata Lemos Crisóstomo \\ Universidade Federal do Triângulo Mineiro - UFTM, Brasil
}

Apoio e financiamento: FAPEMIG

\begin{abstract}
RESUMO
A constituição da identidade docente passa por caminhos teóricos, práticos, sociais, culturais e individuais. Este trabalho objetivou identificar a relação que o professor estabelece entre suas dimensões pessoais e profissionais na sua formação e prática diária. Utilizou três ferramentas para coleta de dados: história de vida temática, registro de campo e grupo focal. Participaram da pesquisa cinco professores da rede pública de ensino de Uberaba e região. Os resultados mostram cinco categorias de acordo com a temática principal: Escolha da carreira docente, Identidade e Perfil Profissional, Dimensões pessoais, Estratégias e Angústias e perspectivas. Pode-se perceber que a identidade profissional e pessoal dos docentes estão (retirada) ligados e podem ser percebidos através das reflexões de suas práticas profissionais. Fazer o caminho reflexivo sobre sua prática permite então ao professor ter ferramentas para atuar de maneira a edificar uma prática de ensino que não se limite à reprodução mecanicista do conhecimento.
\end{abstract}

PALAVRAS-CHAVE: Identidade profissional. Formação de professores. Prática docente.

\section{REFLECTION ON ACTION IN TEACHER TRAINING AND PRACTICE: SELF- KNOWLEDGE AND PROFESSIONAL IDENTITY}

\begin{abstract}
The constitution of the teacher identity goes through theoretical, practical, social, cultural and individual paths. This work aimed to identify the relationship that the teacher establishes between his personal and professional dimensions in his daily training and practice. He used three tools for data collection: thematic life history, field record and focus group. Five teachers from the Uberaba public school system participated in the study. The results show five categories according to the main theme: Career choice, Identity and Professional Profile, Personal Dimensions, Strategies and Anxieties and perspectives. It can be noticed that the professional and personal identity of the teachers are connected and can be perceived through the reflections of their professional practices. Taking the reflective path of practice allows the teacher to have the tools to act in a way to build a teaching practice that is not limited to the mechanistic reproduction of knowledge.
\end{abstract}

KEY WORDS: Professional identity. Teacher training. Teaching practice 


\section{REFLEXIÓN SOBRE LA ACCIÓN EN LA FORMACIÓN Y PRÁCTICA DOCENTE: AUTOCONOCIMIENTO E IDENTIDAD PROFESSIONAL}

\section{RESUMEN}

La constitución de la identidad docente pasa por caminos teóricos, prácticos, sociales, culturales e individuales. Este trabajo objetivó identificar la relación que el profesor establece entre sus dimensiones personales y profesionales en su formación y práctica diaria. Utilizó tres herramientas para la recolección de datos: historia de vida temática, registro de campo y grupo focal. Participaron de la investigación cinco profesores de la red pública de enseñanza de Uberaba y región. Los resultados muestran cinco categorías de acuerdo con la temática principal: Elección de la carrera docente, Identidad y Perfil Profesional, Dimensiones personales, Estrategias y Angustias y perspectivas. Se puede percibir que la identidad profesional y personal de los docentes están (retirada) ligados y pueden ser percibidos a través de las reflexiones de sus prácticas profesionales. Hacer el camino reflexivo sobre su práctica permite entonces al profesor tener herramientas para actuar de manera a edificar una práctica de enseñanza que no se limite a la reproducción mecanicista del conocimiento.

PALABRAS CLAVE: Identidad professional. Formación de professores. Práctica docente

\section{INTRODUÇÃO}

Nos últimos séculos, a educação acompanhava paradigmas cartesianos e mecanicistas da ciência, porém os avanços e novas reflexões quanto à visão de mundo e sociedade alteraram o perfil do profissional da educação para um posto de criatividade em uma nova identidade que busca uma visão integrada dos fenômenos (JUNGES, BEHRENS e TORRES, 2012). Como apontam Costa, Antonioli e Dal-Forno (2012) a formação de professores tem estado no centro dos holofotes das discussões acerca da Educação brasileira e do processo de escolarização, ganhando papel fundamental na constituição de diferentes práticas educacionais.

Por muito tempo as pesquisas que colocavam em foco os professores abordavam, em sua grande maioria, questões da prática e da teoria destes profissionais, deixando de discutir aspectos pessoais e da interação entre subjetividade e perfil profissional.

Burnier et al. (2007) destacam que somente nestas últimas décadas pesquisas que discorrem sobre a história de vida dos professores passaram a se fazer presentes em maior quantidade no meio científico, passando a debater questões referentes ao professor como sujeito que reflete sobre sua ação prática, e não mais como técnica a ser reproduzida.

Esta linha de pensamento não é nova, pois encontra-se em Dewey, na década de 30 citações como "o mero conhecimento dos métodos não basta, pois é preciso que exista o desejo e a vontade de os empregar" (DEWEY, 1989, p. 43). Paulo Freire também dizia, na década de 20, que "A reflexão crítica sobre a prática se torna uma exigência da relação Teoria/Prática sem a qual a teoria pode ir virando blablablá e a prática, ativismo" (FREIRE, 1999, p.24). Marcelo 
Garcia (1992) reforça este pensamento ao dizer que a formação de professores deve possibilitar a reflexão e a tomada de consciência das limitações sociais, culturais e ideológicas da profissão.

Ainda citando Dewey, em 1989 ele traz o conceito de ensino reflexivo, instrumento que produz um movimento ativo e consciente e que dá base para o conhecimento (DEWEY, 1989). Diniz e Campos (2004) ressaltam que a prática reflexiva tem ganhado atenção no meio científico. Apontam que esta se coloca como grande aliada na formação e atuação de professores que ultrapassam as formas simplistas da educação, visto que sempre permeiam questões que vão além do ensinar, perpassando questões sociais e econômicas. Estas afirmações são coerentes com a compreensão de Pimenta (2005), que atribui a esta atividade o processo de construção identitária do professor, num processo contínuo de construção entre os saberes teóricos, o saber-fazer e seus valores pessoais, sentimentos e angústias.

O pensamento de Paulo Freire (1999) citado acima, remete ao que se pode definir como identidade profissional do docente. Segundo Lasky (2005) a identidade profissional é uma construção do "si mesmo" profissional, que evolui ao longo da carreira docente e que pode achar-se influenciado pela escola, pelas reformas e pelos contextos políticos. "[...] inclui o compromisso pessoal, a disposição para aprender a ensinar, as crenças, os valores, o conhecimento sobre a matéria que ensinam, assim como sobre o ensino, as experiências passadas, assim como a vulnerabilidade profissional” (LASKY, 2005, p.909)

Deve ficar claro que o conceito de identidade docente é uma realidade que evolui pessoal e coletivamente, ou seja é algo que se desenvolve durante a vida, como todo processo identitário do indivíduo. Não é da natureza humana, mas sim da condição humana.

Nóvoa (1992) sustenta que a identidade (ser e sentir-se professor), não é um dado nem uma propriedade, muito menos um produto: identidade é um lugar de lutas e conflitos, é um espaço de construção de maneiras de ser e de estar na profissão. Essa autopercepção é o fundamento da identidade pessoal na construção simbólica de si como membro de um grupo.

Portanto é importante entender identidade docente como algo construído tanto externa quanto externamente. Do lado externo encontram-se as atribuições determinadas pelo Estado e pela sociedade sobre o trabalho docente. Internamente tem-se a identidade pessoal, construída e elaborada pelo professor através de sua trajetória como profissional da educação.

Ressalta-se que o professor deve lidar com esses dois lados que, antagônicos, devem se completar, de onde se pode destacar a necessidade de os professores refletirem sobre o processo de construção da identidade profissional em suas várias dimensões. O professor deve procurar superar a identidade atribuída a ele através da produção de práticas sintonizadas com as demandas da realidade. As práticas são construídas a partir das necessidades postas pela 
sociedade. Em outras palavras deve-se ressaltar a importância de constituir a identidade docente sob conteúdos que extrapolem o já cristalizado na prática docente e cunhar-se primordialmente no respeito à dignidade e na autonomia do educador, na ética e no compromisso da ação e reflexão da realidade com forte aporte científico.

Concordando com Galindo (2004), no que se refere à identidade profissional docente, entende-se que se trata de uma construção de sujeitos enquanto profissionais que se inscrevem no jogo do reconhecimento. Esta autora faz um levantamento sobre como a literatura existente faz tentativas de diferenciação entre identidade pessoal e identidade social que está no cerne do reconhecimento. Neste sentido concorda com a distinção que fez Penna (1992, apud GALINDO, 2004), defendendo a ideia de que a identidade pessoal se refere à própria construção pessoal do sujeito, enquanto que identidade social diz respeito a pessoas consideradas membros de uma mesma categoria, independente de conviverem juntos. Cunha et al. (2016) destacam que a formação inicial de professores que já considera o caráter reflexivo pode potencializar a atuação docente, aproximando o professor da realidade escolar.

Neste sentido, esta pesquisa buscou identificar a relação que o professor estabelece entre suas dimensões pessoais e profissionais na sua formação e prática diária. Para tanto, propôs análises reflexivas que envolviam situações de ensino e estratégias frente aos desafios cotidianos impostos por este, além de estabelecer relações entre as histórias de vida dos docentes e suas atuações no dia a dia da profissão.

\section{MÉTODO}

\subsection{Tipo de Estudo}

Trata-se de um estudo exploratório e transversal, dentro da abordagem qualitativa de pesquisa.

\subsection{Sujeitos}

As duas etapas iniciais contaram com cinco professoras da rede pública de ensino de Uberaba e região, enquanto que a última etapa contou com apenas quatro professoras da cidade de Uberaba, por desistência de uma das participantes.

\subsection{Instrumentos}

Esta pesquisa utilizou três ferramentas para coleta de dados: história de vida temática, diários de aula e grupo focal. 
Sivieri-Pereira (2009) refere-se a Martinazzo (2000) esclarecendo que este autor defende que

[...] as histórias de vida constituem um memorial onde se apresenta a compreensão da gênese e da constituição das subjetividades. É uma narrativa com uma grande carga de autocompreensão. Ao relatar a história de vida, o sujeito busca sistematizar os fatos mais significativos que explicam e justificam o processo de constituição de sua singularização/subjetivação (SIVIERIPEREIRA, 2009, p. 81).

A história de vida temática, nesta pesquisa, visava, portanto, abordar questões da vida das professoras que fossem relativas à sua formação acadêmica. Para isto, foram realizadas entrevistas individuais com cada participante, objetivando-se obter maiores informações de cunho pessoal e profissional e possibilitando maior expressividade por parte das professoras.

Os diários de aula buscavam abordar aspectos do dia a dia e de acontecimentos relevantes de sua prática docente, com posterior reflexão sobre a ação (SCHÖN, 1992).

De acordo com Zabalza (2004, p. 27) "os diários de aula, as biografias, os documentos pessoais em geral [...] constituem recursos valiosos de pesquisa-ação ce capazes de instaurar o círculo de melhoria de nossa atividade como professores".

Os registros eram realizados durante e/ou após suas aulas, apontando acontecimentos que poderiam gerar reflexões sobre sua prática cotidiana. Acontecimentos estes que produziram perguntas da equipe de pesquisa que, posteriormente, eram respondidas pelas professoras após reflexões em novas entrevistas que tomavam por base os registros.

Por último foi realizado um Grupo Focal que contou com um mediador da equipe de pesquisa e todas as professoras participantes.

Segundo Carlini-Cotrim (1996, p. 287), em um Grupo Focal

[...] as discussões são conduzidas visando identificar tendências e padrões na percepção do que se definiu como foco do estudo. A análise das discussões vai fornecer pistas e "insight" sobre como um produto, serviço ou plano é percebido.

No caso desta pesquisa foram apresentados estímulos disparadores de temáticas que tocavam em aspectos pessoais e profissionais das participantes, com abertura para reflexões sobre suas práticas e experiências pessoais e profissionais.

A partir da análise dos dados coletados considerou-se que as participantes puderam alcançar benefícios reflexivos, intrínsecos ou psicológicos com os procedimentos realizados durante a coleta de dados. Este fato se mostrou nas falas assistemáticas das participantes em momentos de encerramento de coleta e início de um outro momento de levantamento de dados. 
Manifestaram que foram levadas a uma análise crítica da própria prática docente. Tais procedimentos, também conhecidos como método auto(biográfico), têm sido largamente utilizados em pesquisas sobre formação de professores (NÓVOA; 1992, BUENO, 2002; BORGES, 2008), oportunizando aos participantes um espaço dirigido para o autoconhecimento profissional e crítica-reflexiva de sua prática docente.

Entende-se que nesta pesquisa estes instrumentos foram importantes para a consolidação dos dados pois se acredita, com Cavaco (1991, p. 161) que:

[...] na construção da identidade profissional de professor se entrecruzam a dimensão pessoal, a linha de continuidade que resulta daquilo que ele é, com os trajectos partilhados com os outros, nos diversos contextos de que participa; daqui a importância de considerar os espaços e as situações de reflexão partilhada como facilitadores do desenvolvimento pessoal e profissional e a necessidade de aprofundar seus efeitos formativos, potencializadores de uma apropriação cognitiva dos mecanismos profissionais e de mudanças de perspectivas.

\subsection{Procedimentos para a coleta de dados}

As direções das escolas da rede da cidade de Uberaba foram contatadas para a solicitação de espaço para apresentação do projeto aos professores. Em seguida fez-se contato com os professores para a apresentação do trabalho e aceitação em participar da pesquisa. Após a assinatura do termo de consentimento livre e esclarecido pelas professoras que aceitaram participar, foi feita a escolha de datas e local mais apropriado para a execução das entrevistas. As professoras foram entrevistadas individualmente para o registro da história de vida. Esta entrevista foi gravada e transcrita posteriormente.

Após cada entrevista as professoras eram orientadas a registrarem dia a dia suas ações e reflexões sobre as mesmas em acontecimentos cotidianos ou especiais de seu trabalho. Esses registros foram discutidos com a equipe de pesquisa.

Depois que as cinco professoras passaram por estes dois momentos, quatro delas (houve a desistência de uma das professoras) fizeram uma reflexão grupal, no grupo focal, que também foi gravado e transcrito posteriormente, buscando as ligações entre sua história de vida, seu autoconceito e sua prática docente.

\subsection{Procedimentos para a análise dos dados}

Para a análise dos dados foi utilizada a técnica de Análise de Conteúdo segundo Bardin (1977, p. 42), que define esse procedimento como 
Um conjunto de técnicas de análise das comunicações visando obter, por procedimentos sistemáticos e objectivos de descrição do conteúdo das mensagens, indicadores (quantitativos ou não) que permitam a inferência de conhecimentos relativos às condições de produção/recepção (variáveis inferidas) destas mensagens.

\section{RESULTADOS E DISCUSSÕES}

Para melhor caracterização das participantes, a tabela 1 contém a cidade onde a professora atua, tempo médio de atuação, tipo de escola onde leciona e a disciplina que ministra. Tabela 1. Professoras participantes, cidade, média de tempo de atuação, tipo de escola onde leciona e disciplina que leciona $(n=5)$.

Quadro 1 - Identificação dos participantes

\begin{tabular}{lllll}
\hline Professora & Cidade & $\begin{array}{l}\text { Média de tempo de } \\
\text { atuação }\end{array}$ & $\begin{array}{l}\text { Tipo da escola onde } \\
\text { leciona }\end{array}$ & $\begin{array}{l}\text { Disciplina que } \\
\text { leciona }\end{array}$ \\
\hline E1 & Uberaba & De 15 a 25 anos & Pública - Estadual & Português \\
E2 & Uberaba & De 15 a 25 anos & Pública - Estadual & Matemática \\
E3 & Uberaba & De 5 a 15 anos & Pública - Estadual & Biologia \\
E4 & Uberaba & Mais de 25 anos & Pública - Estadual & Matemática \\
E5 & Delta & De 15 a 25 anos & Pública - Estadual & História \\
\hline
\end{tabular}

Fonte: dados colhidos no momento da entrevista de história de vida

Obs. As professoras foram identificadas com a letra $\mathrm{E}$, seguida de um número

A Tabela1 indica que a maior parte das professoras participantes deste estudo lecionam na cidade de Uberaba, sendo que apenas uma leciona em cidade da região. O termo "Professora" foi utilizado na tabela para indicar que todas as participantes desta pesquisa são do sexo feminino. A feminização do magistério é um tema importante e de grande relevância nas pesquisas sobre identidade docente, mas não é proposta deste artigo se aprofundar em tal tópico, pelo fato de que esta discussão demandaria um artigo com este único objetivo. Apenas aqui corrobora-se com Fontana (2000, apud SIVIERI-PEREIRA, 2008, p. 39), denunciando:

[...] o mascaramento da falta de competência profissional e de compromisso político do docente que se esconde por trás da afetividade e da doação. Explica que o fato contribui para a representação social da carreira docente como própria da mulher, ou seja, uma carreira onde predomina o amor, a vocação e a ausência de profissionalismo.

A média de tempo de atuação mais presente nesta amostra está entre 15 e 25 anos (3 professoras), sendo que as outras duas profissionais estão em diferentes extremos quanto ao 
tempo de atuação, uma mais próxima do início de sua carreira, com média de 05 a 15 anos de atuação, e uma com mais de 25 anos de atuação. Todas as professoras lecionam em escolas Públicas Estaduais, e quanto às disciplinas que ministram, houve variedade, com apenas uma disciplina se repetindo, a disciplina de Matemática.

Visando melhor abordar o conteúdo adquirido nos procedimentos de coleta utilizados, foram criadas cinco categorias de acordo com a temática principal do conteúdo. As categorias que abrangem estas temáticas são Escolha da carreira docente, Identidade e Perfil Profissional, Dimensões pessoais, Estratégias e Angústias e perspectivas.

A categoria Escolha da carreira docente diz respeito a aspectos que de maneira intrínseca e extrínseca influenciaram seu caminho pela carreira docente. Em geral, as professoras tratam a escolha pela docência como uma característica construída durante sua vida, abordando influências de pais e professores com quem conviveram, como evidenciado no trecho:

[...] pra nós descobrirmos essa profissão, de ser professor, é algo que assim, está aflorado desde pequenos. Eu acredito que quando nós nos deparamos desde a nossa infância com histórias contadas, com pessoas que nos dão atenção, desde a educação infantil... então isso fica no cantinho do ser humano. Então esse cantinho é despertado, e pra pessoa virar um professor esse cantinho tem que ser bem trabalhado, porque nós não vemos profissionais da educação falar que viraram professor do nada, né?" (E1).

Embora as crenças de que estas influências não são predestinadas ou divinas sejam amplamente apontadas (NÓVOA, 1992), alguns relatos ainda evidenciam estas crenças, como falas em que o entrevistado dizia sentir a carreira docente dentro de si desde criança. Mas estas falas, muitas vezes, vinham complementadas com a lembrança de que adoravam brincar de escolinha e sempre se comportavam como professoras frente aos seus irmãos, primos ou amigos mais novos. Deve-se considerar que tal brincadeira faz parte do imaginário de crianças que têm a oportunidade de conhecer a escolarização formal (mesmo através de relatos, visitas à escolas e programas de televisão), como faz parte a brincadeira de casinha. Neste sentido ela colabora na elaboração de sentimentos e emoções, mas não se pode considerar como definidora da escolha de uma carreira.

Por vezes esta escolha também é permeada pelas condições sociais e econômicas daqueles que vieram a tornar-se docentes, o que pode ser percebido diante do relato:

O que me fez escolher minha carreira, eu acho que foi a circunstância talvez se eu tivesse, vamos supor que eu tivesse crescido em Uberaba, eu acredito que eu não teria escolhido porque eu teria mais opções”. (E2) 
Observar o passado também constitui uma forma de observar o presente, assim como defende Alves (2012). A autora aponta que conhecer o passado nos auxilia a ver a atual realidade com um olhar diferenciado, moldado por experiências passadas que ainda residem internamente, e que auxilia a refletir sobre este presente, apontando a necessidade de conhecimentos, como os apresentados nesta categoria que remonta momentos embrionários da carreira dos professores participantes.

A forma como o profissional identifica sua própria atuação fornece material para a conceitualização de outra categoria, denominada Identidade e Perfil Profissional. Esta categoria aponta para aspectos que as professoras identificam como partes constituintes de sua atuação profissional, e reconhecem que sua atuação vai além da relação do ensino e da própria sala de aula, abordando também aspectos de caráter social e até pessoal de seus alunos. "Ao mesmo tempo, vejo o quanto a figura do professor é significativa na vida deles. Torna-se referência, o que nos torna mais responsáveis em nossa atitude junto deles".(E3)

Estas reflexões indicam que, assim como colocado por Costa, Antonioli e Dal-Forno (2012), é solicitado do professor criticidade e flexibilidade de seus conteúdos para lidar com situações diferentes daquelas que vivem ou vivenciaram, colocando a prática reflexiva como um ponto necessário para estas modificações. Do mesmo modo, perceber estas diferenças dá ao professor maneiras de potencializar suas habilidades e a de seus alunos.

Outros aspectos desta categoria fazem referência a como as professoras se reconhecem em suas práticas e como esta se relaciona com características pessoais de cada docente

E os meninos, eu não sei se é o meu perfil, eu sou aquela brava, que dá bronca, mas os meninos eles têm carinho por mim, eles vêm a confiar em mim, né, tem um problema eles já vem logo 'professora, o que que pode ser feito ai' e tal, e eu já quero ver se dou conta de resolver aquilo, mas não... sabe? (E4)

Este ponto será melhor discutido na categoria Dimensões Pessoais deste artigo, mas é importante ressaltar que os estudos desenvolvidos pelo Grupo de Pesquisas e Estudos sobre Formação de Professores (GPEFORM), do qual esta pesquisa faz parte, têm cada vez mais constatado a relação intrínseca existente entre a formação da prática docente e a formação de sua identidade, antes da formação da identidade profissional. Entende-se este fato como perfil profissional, ou seja, como o professor constrói sua maneira de saber e fazer sua prática, ou melhor, como se posta e se mostra como professor.

A constituição da identidade docente, ou o "ser-professor", é construída por meio de um longo processo que deve permitir tempo para a assimilação da formação, para aprender como agir, para decidir o caminho a seguir e se apropriar do sentido de ser um formador de outras 
pessoas. (IZA, et al, 2014). Neste sentido a fala da professora 3 mostra um caminho percorrido até chegar à docência:

E ai a minha experiência na UFMG foi muito importante, porque eu vivi 2 anos dentro do laboratório e aprendi tudo praticamente, de laboratório. E ai fui, voltando, na faculdade eu também fui monitora de disciplina, fiz estágio em indústria também, procurei diversificar pra quando eu formar eu tivesse uma base pra eu saber escolher qual é o caminho que eu queria seguir. [...]. Daí mesmo trabalhando na faculdade, comecei a dar aula, comecei numa escola de ensino fundamental com laboratório, fui dar aula pros meninos, ai a diretora da escola gostou do meu trabalho e me convidou para assumir uma sala de aula, assim, da quinta série, era quinta série até a oitava série. (E.3)

Iza (2014, p. 276-277) ainda afirma que

[...] os saberes se constituem como algo plural que foi construído no âmbito sociocultural da profissão, podendo apresentar modificações com o passar do tempo, incluindo informações, crenças, habilidades e aptidões relacionadas a uma determinada profissão. Dessa forma, a identidade que cada professor constrói baseia-se em um equilíbrio único entre as características pessoais e os percursos profissionais construídos ao longo da história de vida.

Esta afirmação também encontra respaldo nas palavras das professoras entrevistadas:

A minha formação, como um todo, ela foi uma formação conteudista. Então, hoje eu estou buscando referências, porque falar em conteúdo, em formação conceitual, procedimental e atitudinal. Então eu estou buscando me atualizar para eu conseguir trabalhar dessa maneira. [...]. Estou nesse processo de autoconhecimento e de formação, sabe, de adequação. (E.3)

Quanto ao perfil profissional, como professora hoje, vejo que eu aprendo um pouquinho a cada dia. Sou uma pessoa, assim, um pouco séria, tímida, mas, vejo que a profissão me satisfaz muito, porque consigo interagir, consigo criar novos vínculos, sempre deixo os alunos darem sugestões, então vejo que aquela minha crença anterior que o professor tinha uma autonomia muito rígida, ditadora, entre aspas, não existe, porque você tem que sair ali da frente, interagir com os alunos, deixar eles também colocarem muitas sugestões, trazerem ideias, trazerem novidades, só assim que flui. (E.1)

Mockler (2011, apud IZA et al, 2014) fala de três dinâmicas que envolvem a identidade docente ou o "ser professor(a)": aprendizagem profissional, ativismo docente e desenvolvimento pessoal, que resultam "na melhoria qualitativa do envolvimento e compreensão de si próprio, do campo de trabalho ou das esferas políticas" (p. 276).

Iza (2014) ainda chama a atenção para que deve-se reconhecer a preponderância de uma epistemologia da prática contrapondo-se ao reducionismo de técnicas que sabidamente contribuíram para a crise da identidade docente.

$\mathrm{Na}$ esteira do autoconhecimento, ou no que se refere à compreensão de si próprio, e consequente construção da identidade profissional, vemos que a categoria denominada Dimensões pessoais aponta para questões da vida cotidiana das professoras e de suas 
características pessoais que transpõem a barreira entre profissional e pessoal, evidenciando que esta divisão não ocorre na prática destas docentes. Como é apresentado em alguns relatos, questões pessoais estão muitas vezes em contato com o cotidiano profissional, tanto na direção pessoal-profissional quanto na profissional-pessoal, como aponta a fala: “... a pessoa, o ser integral, a pessoa é um ser integral, né, e que somente uma pequena parcela dela é o profissional, não é...”. (E3)

André e Pontin (2010) ressaltam que estas reflexões possibilitam ao professor rever suas questões em um processo que também é de aprendizagem para ele, o que lhe dá condições para pensar novas formas de abordar seus alunos e o próprio ensino, como pode ser percebido no trecho:

Não dá para separar o que somos do que estamos compartilhando, ensinando, este é o desafio pois hoje há muita liberdade que aprendi como libertinagem, tenho que sempre rever meus conceitos para não perder a paciência com os alunos e compreender que o mundo mudou, evoluiu e eu preciso viver o hoje e não o ontem. (E1)

Em alguns relatos as docentes apontam constante influência que têm sobre os alunos e também destes em seu cotidiano, como evidenciado nos seguintes trechos: “...Mas que realmente não é fácil distinguir a todo momento o aspecto pessoal do profissional não, também observo que nós levamos muita coisa do pessoal pra sala de aula, e as vezes... é, e ao contrário...”. (E1)

Eu não tenho, eu vou, eu posso chegar mal, os meninos já sabem, eu piso na sala de aula, os meninos 'ih, professora, a senhora tá mal hoje ein', ai eu falo 'gente, não me estressa não, porque vocês sabem que quem vai levar é vocês né, então fica... dá um tempo'.. (E4)

Estas reflexões levam a citar novamente Nóvoa (1992, p.25) que apesar de antigo na data é tão atual no conceito:

O professor é a pessoa. E uma parte importante da pessoa é o professor (Nias, 1991). Urge por isso (re)encontrar espaços de interação entre as dimensões pessoais e profissionais, permitindo aos professores apropriar-se dos seus processos de formação e dar-lhes um sentido no quadro das suas histórias de vida.

Este trabalho se interessou por estes espaços de interação entre as dimensões pessoais e profissionais. É a questão de uma parte importante da pessoa ser o professor. Seria o professor se descobrir como profissional que encontra na profissão o complemento de si, que toda sua personalidade indica ser ele realmente uma “pessoa-professor". Seria acreditar que só se pode ser um bom professor se as competências e habilidades profissionais e as competências 
e habilidades pessoais estiverem em sintonia, fizerem parte do mesmo processo de desenvolvimento

Outro ponto de destaque, e que recebe grande influência das dinâmicas pessoais de cada professor, refere-se às Estratégias que os profissionais encontram para efetivar sua prática de maneira positiva e lidar com as diferenças do contex to escolar. Ao refletir sobre sua prática, as docentes apontam para diferentes ferramentas que utilizam para envolver seus alunos em atividades de aprendizagem, ora de forma democrática, ora por formas com caráter mais autoritário.

[...] nas minhas aulas é combinado. Primeiro dia já tá avisado, na minha aula não usa isso, não faz isso, não faz aquilo. Ah, alguns tentam burlar? Mas é só o começo, e depois vai e é tudo um combinado. É lógico que o combinado maior sou eu que faço, mas eles acatam né, vai indo acostuma com aquilo.... (E4)

Eu procuro levar curiosidades, conhecimento diferente, né, pra que eles possam conhecer coisas novas, né, levo pro laboratório, faço um trabalho diferente, pra poder suprir, né... e também eu entendo assim, uma sala de aula tudo quietinha, eu entendo que não tá produzindo, sabe... eu acho que os meninos também tem que ter um pouquinho de caos pra criatividade também aflorar, né. (E3)

Em relação às maneiras de ensinar Tardif (2005, p. 132) enfatiza que

Ensinar é, portanto, fazer escolhas constantemente em plena interação com os alunos. Ora, essas escolhas dependem da experiência dos professores, de seus conhecimentos, convicções e crenças, de seu compromisso com o que fazem de suas representações a respeito dos alunos e, evidentemente, dos próprios alunos.

Portanto pensar no ensino de forma mais tradicional ou inovadora também vai depender de quem é esse professor, das escolhas que faz perante a vida e a sua profissão, ou seja sua identidade profissional.

O uso das tecnologias também tem ganhado um espaço significativo no ambiente da educação como um todo. Cada vez mais a tecnologia se torna parte do cotidiano social do mundo atual, e um dos desafios encontrados é a utilização destas tecnologias pelas amplas e diversas camadas sociais. A escola encara, neste movimento, duas novas realidades, a de manipular tecnologia de forma que não atrapalhe o ensino e a de utilizar estes mecanismos a seu favor. Angotti e Auth (2001) apontam a necessidade que a escola tem em adequar a evolução tecnológica a seu favor e também o papel de proporcionar aos seus alunos capacitação para acompanhar estas evoluções, assim como também é percebido nas falas das participantes desta pesquisa: 
[...] hoje em dia devido a tecnologia, as mídias, muitas contribuições são negativas mesmo, porque isso é aguçado neles desde pequenos...então nós vemos que é, eles trazem tudo pra sala de aula, e eles não tem um limite né, em que momento falar, em que momento...exemplificar, eles trazem e querem despejar aquilo ali a qualquer hora em qualquer dia. (E1)

É percebido pelas professoras que a atuação conjunta traz benefícios tanto para sua prática quanto para o ensino que ultrapasse as barreiras da mecanização, além de criarem mais oportunidades para o desenvolvimento e o uso da tecnologia. Um ponto destacado e elogiado, foi a atuação do PIBID junto às escolas, em um contato entre as universidades e o contexto no qual se inserem, tal como problematiza Pimenta (2005) ao pontuar que existem transformações quanto às finalidades das universidades públicas e do ensino superior em geral.

Por outro lado, as falas levam a questionar se não estaria existindo, por parte das professoras, uma "entrega" para os mais novos, os do PIBID, a responsabilidade da modernização da escola, como no caso do uso das tecnologias. Uma aparente desistência de aprimoramento.

[...] o professor às vezes não tem tempo pra ter a criatividade de montar aulas diferenciadas, os alunos do PIBID, eles estão pra isso, né, então eles tem tempo, tão, tem mais acesso à tecnologia, então eles vão trazer coisas novas para os professores, né. E aí é uma..., o professor transmite a experiência que ele tem, e os alunos trazem, traz coisas novas. (E3)

Segundo Santos (2009), o professor busca em seu dia a dia estratégias para lidar com os desafios advindos da prática educacional, dentre os quais a não aprendizagem, a indisciplina dos alunos e o cansaço do profissional. Dentre as ferramentas que encontra para este enfrentamento, destacam-se os modos alternativos de se efetivar sua prática, como novos modelos de ministrar aula, diferenças na fala ao abordar os alunos e até improvisos. Este modo de abordagem que não se limita à transmissão técnica de conhecimentos pode ser evidenciado no seguinte trecho:

[...] hoje eu não vejo mais aquela também aula, de despencar conhecimento igual eu tive a ansiedade, sabe? Então hoje, eu por exemplo vejo também, é o atitudinal, é procedimental, é o aluno pegar e fazer, sabe? [...] eu tô nesse desafio, né, de por exemplo conseguir pegar um tema das ciências, da biologia, e por exemplo, lixo: gente, vamos trazer material reciclável, pra gente montar uma maquete. Eles vão aprender muito mais, do que se eu ficar lá na frente, falando, falando, falando, falando sobre lixo.. (E3)

Retoma-se aqui que mesmo com as mudanças nos estilos e métodos do ensinoaprendizagem em suas mais diversas exemplificações, os docentes não abandonam o papel do professor enquanto agente do saber que favorece esta equação contínua e bidirecional do ensino 
- aprendizagem. Silva (2002) destaca que o papel do professor na explicação dos conteúdos ensinados ainda se mostra como estratégia eficaz neste processo, podendo ressaltar que, como citado pela participante desta pesquisa em sua fala, o ensino e a explicação dos conteúdos não se resumem a uma aula tradicional que se limita a lousa, mas sim a formas dinâmicas que maximizam os potenciais dessa cultivação de conhecimento.

Algumas dificuldades também são encontradas no campo das Estratégias, com evidentes pedidos de ajuda para encontrar possíveis soluções para as realidades vivenciadas, como pode ser percebido no seguinte trecho, que toca em questões sobre sexualidade: “...como é que eu vou, como que eu vou ser orientada, eu, com 60 anos, que não admito... não é nem preconceito, é questão cultural, dentro de mim, respeitar é obrigado a todo mundo, uma homossexualidade." (E4)

Nardi e Quartiero (2012) indicam que esta realidade se estende pela nação brasileira, não sendo um fato concentrado no Triângulo Mineiro como nesta amostra. É bom lembrar que providências para a construção de uma comunidade que compreende a diversidade dentro da escola já são tomadas em todo o Brasil, apesar de um cruel recrudescimento nos últimos 2 anos com movimentos contrários, como a luta contra a ideologia de gênero nas escolas e o surgimento do "Escola sem Partido".

Nardi e Quartiero (2012) citam um trabalho desenvolvido no município de Porto Alegre em que um grupo constituído por profissionais da área da psicologia, militantes dos assuntos e professores que se interessavam na temática, se reuniam em formato de grupo reflexivo com algumas palestras acerca do tema. Apesar de importante o evento encontrou dificuldades de adesão até mesmo por não ser um programa obrigatório, ficando a critério dos professores e das escolas a partir de suas demandas e das realidades enfrentadas por cada parte.

Por fim, temos a categoria referente às Angústias e perspectivas das professoras quanto ao sistema de ensino. Foi evidente a insatisfação das docentes quanto à desvalorização da carreira, remuneração desproporcional, dificuldades de socialização e continuidade de projetos e falta de apoio profissional.

Bons resultados na educação têm que ser a longo prazo, né...não se consegue um bom resultado pra determinado projeto em dois, três anos. Tem que ser algo mais experimentado, mais vivenciado, melhorado, né... E isso que você falou é muito pertinente, é, na escola pública estadual, tudo começa e não termina. (E2)

A prática profissional traz a reflexão de que talvez nunca tenha se exigido tanto do papel de um professor quanto nos tempos atuais, onde a escola cada vez mais tem a função de não 
somente transmitir e reproduzir conhecimentos já existentes, mas também criar novas condições para que novos conhecimentos sejam desenvolvidos e aplicados tanto em relação a desenvolvimentos tecnológicos quanto em atuações profissionais que modificam a sociedade. Percebe-se nos dados colhidos nesta pesquisa, falas de participantes que coincidem com essas reflexões, onde a busca por novos estilos de desenvolvimento das escolas vai modificando também a própria formação e especialização das professoras em suas implicações na prática:

É, eu percebo que na educação a gente não pode estagnar, assim como nas outras áreas também, mas a nossa área nos cobra muito, então assim, de fazer um curso, de estar procurando uma formação mesmo, superior, né. [...] esse é o caminho, igual a colega falou, não tem como ficar sem estudar pra dar aula hoje, foi-se o tempo em que se formava e era o profissional $x$, bom, excelente. (E1)

Lima e Lima-Filho (2009) e Batista et al (2010) põem em questão que o ambiente escolar precarizado coloca o docente em condições de definhamento de sua própria saúde. A falta de aparatos físicos e apoio administrativo influenciam na queda de rendimento e motivações dos professores na busca de melhores condições de execução de seus trabalhos. Os trechos seguintes evidenciam os pedidos dos professores por mais apoio institucional e profissional visando a potencialização de suas atividades na busca de um processo de ensino eficaz.

Então, mas ninguém te dá uma dica, uma luz no fim do túnel, falar tipo, você poderia fazer tal, isso, alguma coisa, ou algum lugar que fez diferente, que deu certo, como, porque outros países são diferentes, mas aí outras realidades, outras culturas, mas e na nossa? Ninguém tenta, ninguém tem uma luz no fim do túnel. E a gente confia naquilo que a gente faz, eu pelo menos faço confiando naquilo no que eu tô achando que tá fazendo o melhor, mas e aí, não tá dando certo. Já tem anos e anos não dando certo, e ninguém descobre o porquê que não dá certo. (E4)

Eu penso que, na escola, precisava assim, de um assistente social, de um psicólogo, não é? Pra poder realmente fazer uma equipe multidisciplinar, com pedagogo, né, a parte administrativa, a gestão, não é, pra poder cuidar.. (E3)

Outro ponto apontado como limitação para uma prática mais integrada reside no destaque que as professoras dão à falta de comunicação entre as diferentes práticas e disciplinas que se desenvolvem em um mesmo meio escolar. Citam que tal procedimento dificulta as atividades de interdisciplinaridade e melhor amarração dos conteúdos ministrados como constituintes da realidade social a qual a escola está incluída. Este destaque pode ser percebido na seguinte fala: 
E na escola não existe, não tem uma pauta de reunião, não tem uma definição do que vai ser feito.[...] não teve alguém pra ir lá e dizer: isso foi bom, isso foi ruim, ou sei lá, fazer outras vezes, dizer o que que deu certo, o que não deu certo, fazer uma divulgação né. Então eu acho que falta muito isso na escola, as experiências que foram feitas, né. Eu levei um palestrante lá que os meninos, razoavelmente, mas eu fiquei apaixonada, né. Assim, então, a gente faz algumas coisas dentro da escola, que assim, não é divulgado, o outro não vê né, o outro as vezes comenta, um fala, mas, não, sei, eu não sei o que acontece. (E4)

Neto (2014) aponta que a comunicação entre professores de diferentes áreas do conhecimento pode render frutos muito positivos para o desenvolvimento da interdisciplinaridade. Reflete, também, que profissionais que façam essa relação conseguem desenvolver melhor as relações entre teoria e prática, além de poderem realizar essa atividade de forma reflexiva.

Como é ressaltado no trecho abaixo, as condições de jornada trabalho a que o professor tem que se submeter para conseguir ter a prática docente como única fonte de renda se encontram precárias, tanto em relação à desvalorização do profissional, da remuneração e também das próprias condições de trabalho. "o professor tem que se submeter a jornada tripla pra poder conseguir tirar um salário que seja digno pra pagar as contas". (E3)

Segundo Saviani (2009), estas condições precárias a que o professor se submete afeta tanto o professor quanto a própria comunidade que usufrui de seus serviços, e destaca que estas condições neutralizam o trabalho do professor bem formado e precariza ainda mais a formação de novos docentes.

Outra informação necessária de ser observada está em Souto e Paiva (2013), que revelam em seu estudo, que a carreira docente não se mostra tão atrativa a ponto de conquistar e manter profissionais na área da docência, como foi apresentado na fala de uma das entrevistadas que leciona matemática, assim como os professores do estudo citado:

Porque quando você tá frustrado você não tá feliz, se você não tiver feliz acho que você não deveria estar no aquário, né. Eu gostaria de ser esse peixe colorido que tá no aquário pequeno e quer ir pro aquário maior ainda, mas que seja um aquário, né. Mas eu não me vejo, assim, com esse desejo de ir pra um aquário maior ainda, né. (E2)

Como já destacado anteriormente, esta frequente desmotivação para continuar e crescer na área da docência muitas vezes está relacionada a condições precárias que esta carreira encara, principalmente na esfera pública de ensino, indicando novamente a necessidade de uma reforma intensa do sistema de ensino (SOUTO \& PAIVA, 2013; SAVIANI, 2009). Mais uma vez são 
destacados fatores que contribuem com este baixo interesse em progredir ou até mesmo continuar na docência, e dentre eles se destacam baixos salários e inadequada infraestrutura.

Ao final do Grupo Focal, último instrumento de coleta de dados da pesquisa as professoras agradeceram a oportunidade de participar e contribuir com a construção do conhecimento nesta área. Algumas falas são destacadas, reiterando as possibilidades de reflexão incitadas por cada etapa desta pesquisa que ocorre com a contribuição ativa de suas participantes:

[...] eu quero te agradecer a oportunidade de participar, sabe, tá sendo muito bom porque eu também tô refletindo sobre. (E3)

[...] eu acho que é uma experiência que acrescenta. E a gente tem aprendido, pode ter aprendido algo. Pelo menos só o fato de você parar pra pensar "será que tá certo?", pra se fazer uma pergunta dessa, né, porque já surge uma dúvida, né. E levantar uma dúvida talvez seja um caminho pra você buscar uma resposta. (E2)

E essas pesquisas que a professora Helena proporcionou que a gente participasse, ajuda a refletir mesmo, ajuda a repensar, ajuda a ver mais defeitos em nós mesmos. As vezes nos sentimos totalmente capacitados e achamos que estamos no caminho certo, aí lê uma frase ou se observa, olha no espelho novamente, você fala: "tenho que mudar, não é assim". Ah, é difícil mudar? É, mas tem que mudar. É um trabalho, um trabalho processual. (E1)

Pode ter certeza, eu acho que valeu. Pelo menos alguém escutou o que a gente falou e o que a gente pensa, né. E assim, foi muito importante [...]. (E4)

A metodologia utilizada nesta pesquisa se mostrou como uma atividade que permitiu e incitou a mudança no cotidiano das professoras enquanto profissionais e enquanto pessoas, tal como destacam Garrido e Carvalho (1999) e Souza et al. (2012), e como foi observado nas falas apresentadas durante o desenvolvimento da mesma. A possibilidade de olhar para estes dados serve como motor para questionamentos, que por sua vez servem como catalisadores para mudanças, que muitas vezes fazem moldar outros perfis que contribuam com a educação. Mas os professores devem ser amparados profissionalmente (GARRIDO \& CARVALHO, 1999), pois trazem consigo uma carga emocional muito grande, tal como já foi destacado pelas participantes deste estudo.

\section{CONSIDERAÇÕES FINAIS}

Pode-se perceber que os professores compreendem a íntima relação que existe entre a identidade profissional e a identidade pessoal, que pode ser confirmada através das reflexões de suas práticas profissionais. Os professores chegam à sala de aula permeado por suas 
vivências pessoais e naquele ambiente se colocam de acordo com estes referenciais. Este movimento também ocorre na direção inversa, pois as características das vivências profissionais ultrapassam a barreira entre pessoal-profissional e passam a ser partes constituintes da identidade do professor.

É observado que o professor está frequentemente atrelado ao desenvolvimento social, e cada vez mais este papel vem ganhando força e visibilidade, embora as condições para a manutenção e atratividade desta carreira não estejam em seus melhores momentos. Temas diversos como desenvolvimento tecnológico e sexualidade estão frequentemente perpassando seu cotidiano, e a possibilidade da reflexão, aliada à compreensão histórica de suas próprias vidas e do desenvolvimento educacional possibilitam novas formas de intervenção social.

Outra grande retribuição para com a sociedade ocorre por meio do trabalho contínuo que vem se desenvolvendo junto às universidades, que novamente retornarão suas formações à comunidade como um todo. Importante destacar que estar em meio a tantas modificações que afetam o ser profissional e pessoal muitas vezes requer um aparato emocional fortificado, indicando a necessidade do constante trabalho conjunto das equipes de educação, políticas públicas e saúde, de forma a serem fornecidos ao professor capacidades para trabalhar com dignidade.

Fazer o caminho reflexivo sobre sua prática permite então, ao professor, ter ferramentas para atuar de maneira a edificar uma prática de ensino que não se limite à reprodução mecanicista do conhecimento, um trabalho que seja desenvolvido de forma a questionar e entender a relação entre prática e conhecimento teórico de formas muitas vezes interdisciplinares. As ferramentas desta pesquisa se mostraram efetivas no auxílio deste processo contínuo, eliciando temáticas embutidas que puderam ser verbalizadas neste encontro consigo e com o outro.

\section{REFERÊNCIAS}

ANDRÉ, Marli Eliza D. A.; PONTIN, Marta M. D. O Diário Reflexivo, Avaliação e Investigação Didática. Revista Meta: Avaliação, vol. 2, n.4, p. 13-30. 2010.

ANGOTTI, José A. P.; AUTH, Milton A. Ciência e tecnologia: implicações sociais e o papel da educação. Ciência \& Educação, vol. 7, n. 1, p. 15-27. 2001.

ALVES, Cláudia. O educador e sua relação com o passado. Educação em Revista, vol.28, n.3, p. 205-217, set. 2012.

BARDIN, Laurence. Análise de Conteúdo. Tradução Luís Antero Reto e Augusto Pinheiro. Lisboa: Edições 70, 1977. 
BATISTA, Jaqueline Brito et al. O ambiente que adoece: condições ambientais de trabalho do professor do ensino fundamental. Cadernos Saúde Coletiva, vol. 18, n. 2, p. 234-242. 2010.

BORGES, Sheila S. C. B.. A identidade do professor do ensino médio: autoconhecimento e conscientização. 2008. Dissertação (Mestrado em Educação) - Universidade Católica de Santos, Santos-SP. Disponível em: 〈http://biblioteca.unisantos.br:8181/handle/tede/148>. Acesso em: 10 ago. 2016.

BUENO, Belmira Oliveira. O método autobiográfico e os estudos com histórias de vida de professores: a questão da subjetividade. Educação e Pesquisa, São Paulo, v.28, n.1, p. 11-30, jan./jun. 2002. Disponível em: 〈http://www.scielo.br/pdf/ep/v28n1/11653.pdf>. Acesso em: 10 jun 2017.

BURNIER, Suzana et al. História de vida de professores: o caso da educação profissional. Revista Brasileira de Educação, 12(35), p. 343-358, maio/ago 2007. Disponível em: <http://www.scielo.br/pdf/rbedu/v12n35/a13v1235.pdf>. Acesso em 10 jun. 2017.

CARLINI-COTRIM, Beatriz. Potencialidades da técnica grupo focal em investigações sobre abuso de substâncias. Rev. Saúde Pública. V.30, n.3. São Paulo, p.285-293, jun. 1996.

CAVACO, Maria Helena. Ofício do Professor: O Tempo e as Mudanças. IN: NÓVOA, António. Profissão Professor. Porto. Portugal: Porto Editora, 1991, p. 155-191.

COSTA, Anelise dos Santos; ANTONIOLI, Camyla; DAL-FORNO, Letícia F. O professor reflexivo e o reconhecimento das altas habilidades/superdotação. In: IX SEMINÁRIO DE PESQUISA EM EDUCAÇÃO DA REGIÃO SUL, 2012. Anais... Disponível em: $<$ http://www.ucs.br/etc/conferencias/index.php/anpedsul/9anpedsul/paper/viewFile/2578/480. Acesso em 10 jun 2016.

CUNHA, Regiane Stafim et al. Formação inicial docente e suas relações dentro do âmbito escolar. Ciência \& Educação, v. 22, n. 3, p. 585-596, 2016.

DEWEY, John. Cómo pensamos. Barcelona: Paidós, 1989.

DINIZ, Renato Eugênio da Silva; CAMPOS, Luciana Maria Lunardi. Formação inicial reflexiva de professores de Ciências e Biologia: possibilidades e limites de uma proposta. Revista Brasileira de Pesquisa em Educação em Ciências, vol. 4, n.2, p. 27-39. 2004.

FONTANA, Roseli A C. Como nos tornamos professoras? Belo Horizonte: Autêntica, 2000.

FREIRE, Paulo. Pedagogia da Autonomia. Saberes necessários à prática educativa. São Paulo: Paz e Terra, 1999

GALINDO, Wedna Cristina Marinho. A construção da identidade profissional docente. Psicologia Ciência e Profissão, v. 24, n. 2, p. 14-23, jun. 2004. Disponível em: $<$ http://www.scielo.br/scielo.php?script=sci_arttext\&pid=S141498932004000200003\&lng=en\&nrm=iso > . Acesso em: 10 jan. 2017

GARRIDO, Elsa; CARVALHO, Ana Maria Pessoa. Reflexão sobre a prática e qualificação da formação inicial docente. Cadernos de Pesquisa, n. 107, p. 149-168. 1999. Disponível em: http://www.scielo.br/pdf/cp/n107/n107a06.pdf. Acesso em 20 jun. 2016. 
IZA, Dijnane Fernanda Vedovatto et al. Identidade docente: as várias faces da constituição do ser professor. Revista Eletrônica de Educação, v. 8, n. 2, p. 273-292, 2014. Disponível em: http://www.reveduc.ufscar.br/index.php/reveduc/article/view/978. Acesso em 10 jun. 2017.

JUNGES, Kelen S.; BERRENS, Marilda Aparecida; TORRES, Patricia L. Desenvolvimento profissional e a prática reflexiva: uma experiência de formação de docentes universitários no nível stricto sensu no paradigma da complexidade. Revista e-Curriculum, v.8, n.1, abr. 2012. Disponível em: <http://revistas.pucsp.br/index.php/curriculum/article/view/9028>. Acesso em: 10 jun. 2017.

LASKY, Sue. A sociocultural approach to understanding teacher identity, agency and professional vulnerability in a context of secondary school reform. Teaching and Teacher Education, n. 21, p. 899-916, 2005.

LIMA, Maria de Fátima E. Mendonça; LIMA FILHO, Dario de Oliveira. Condições de trabalho e saúde do/a professor/a universitário/a. Ciências \& Cognição, Rio de Janeiro, v.14, n. 3, p. 62-82, nov. 2009. Disponível em $<$ http://pepsic.bvsalud.org/scielo.php?script=sci_arttext\&pid=S1806-

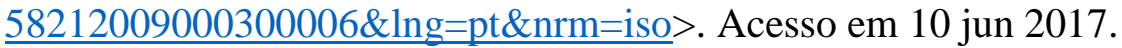

MARCELO GARCIA, Carlos. A formação de professores: centro de atenção e pedra-detoque. In: NÓVOA, António (Org.). Os professores e a sua formação. Lisboa, Portugal: Publicações dom Quixote, 1992, p. 51-76.

MARTINAZZO, Celso José. Apresentação. In: Histórias de Vida de Professores: formação, experiências e práticas. Ijuí: Unijuí, 2000, p. 53-78.

NARDI, Henrique Caetano; QUARTIERO, Eliana. Educando para a diversidade: desafiando a moral sexual e construindo estratégias de combate à discriminação no cotidiano escolar. Sexualidad, Salud y Sociedad, Rio de Janeiro, n.11, p. 59-87. Ago. 2012. Disponível em: $<$ http://www.scielo.br/scielo.php?script=sci_arttext\&pid=S1984-

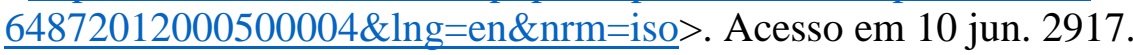

NETO, Eulália. Os projetos de trabalho: uma experiência integradora na formação inicial de professores. Revista Portuguesa de Educação, vol. 27, n.2, p.83-107, 2014. Disponível em: <http://www.scielo.mec.pt/pdf/rpe/v27n2/v27n2a05.pdf>. Acesso em: 10 jun. 2017.

NÓVOA, António. Os professores e as histórias da sua vida. In: NÓVOA, António (Org.). Vida de professores. 2. ed. Porto: Porto, p. 11-30, 1992.

PIMENTA, Selma Garrido. Professor - pesquisador: mitos e possibilidades. Contrapontos, vol. 5, n. 1, p. 9-22. 2005.

SANTOS, Gideon Borges dos. Os professores e seus mecanismos de fuga e enfrentamento. Trabalho, educação e Saúde, v. 7, n. 2, p. 285-304, out. 2009. Disponível em: $<$ http://www.scielo.br/scielo.php?script=sci_arttext\&pid=S198177462009000200006\&lng=en\&nrm=iso>. Acesso em: 10 jun. 2017.

SAVIANI, Dermeval. Formação de professores: aspectos históricos e teóricos do problema no contexto brasileiro. Revista Brasileira de Educação, v. 14, n. 40, p. 143-155, 2009. 
SCHÖN, Donald A. Formar professores como profissionais reflexivos. In NÓVOA, António (Org). Os professores e a sua formação. Lisboa, Portugal: Publicações Dom Quixote, 1992, p. 77-91.

SILVA, Marilda da. Explicação do conteúdo: elemento estruturante da aprendizagem eficaz. Cadernos de Pesquisa, n. 115, 195-205. Março 2002. Disponível em:

〈http://www.scielo.br/pdf/cp/n115/a08n115.pdf >. Acesso em 10 jun. 2017.

SIVIERI-PEREIRA, Helena. de Ornellas. O professor principiante e os espaços de interação entre as dimensões pessoais e profissionais da carreira docente. 2008. Tese (Doutorado em Psicologia) - USP Ribeirão Preto, 2008.

SOUTO, Romélia Mara Alves; PAIVA, Paulo Henrique A. Avelar. A pouca atratividade da carreira docente: um estudo sobre o exercício da profissão entre egressos de uma Licenciatura em Matemática. Pro-Posições, v. 24, n. 1, p. 201-224, jan. 2016. Disponível em: $<$ https://periodicos.sbu.unicamp.br/ojs/index.php/proposic/article/view/8642669>. Acesso em: 03 out. 2016.

SOUZA, Ana Paula Gestoso de et al . A escrita de diários na formação docente. Educação em Revista, Belo Horizonte, v. 28, n. 1, p. 181-210, mar. 2012. Disponível em:

$<$ http://www.scielo.br/scielo.php?script=sci_arttext\&pid=S0102$\underline{46982012000100009 \& \operatorname{lng}=e n \& n r m=i s o}>$. Acesso em: 10 jun. 2017

TARDIF, Maurice. Saberes docentes e formação profissional. 5 ed. Petrópolis: Vozes, 2005.

ZABALZA, Miguel A. Diários de aula: um instrumento de pesquisa e desenvolvimento profissional. Porto Alegre: Artmed. 2004

\section{SOBRE OS AUTORES}

Helena de Ornellas Sivieri-Pereira é Doutora em Psicologia pela USP de Ribeirão Preto e Mestre em Psicologia Escolar pela PUC de Campinas. Docente do Departamento de Psicologia da Universidade Federal do Triângulo Mineiro (UFTM) e do Programa de Pós-Graduação em Educação da mesma instituição.

E-mail: helena.sivieri@gmail.com

Dennis Gabiatti Lopes é graduado em Psicologia pela Universidade Federal do Triângulo Mineiro (UFTM) e atua como psicólogo escolar no Colégio Opção (Uberaba, MG).

E-mail: dennis.gabiatti@gmail.com

Renata Lemos Crisóstomo é graduanda em Psicologia na Universidade Federal do Triângulo Mineiro (UFTM).

E-mail: renatacrisostomo@gmail.com 